\title{
Documentation of the Salivary Gland Tumors: An institutional data from Turkey
}

\author{
Ulku Kucuk $^{1}$, Gamze Akoz ${ }^{1}$, Ebru Cakir ${ }^{1}$, Emel Ebru Pala ${ }^{1}$, Umit Bayol ${ }^{1}$, Murat Gumussoy ${ }^{2}$, \\ Ibrahim Cukurova ${ }^{2}$
}

\begin{abstract}
Objective: World-wide series show some differences in the incidence and clinicopathologic features of salivary gland tumors.

Methods: A total of 248 cases of SGTs diagnosed in our hospital between 1998 and2013 were reviewed with respect to their clinicopathologic features.

Results: There were 128 male and 116 female patients with a mean age of 49.2. Of these 248 tumors 214 were benign and 34 were malignant. The mean age of the patients with benign tumors was 48.6 years and with malignancies was 55.3 years. The most common site was the parotid gland $(83.5 \%)$ followed by submandibular and minor ones. Pleomorphic adenoma $(50.4 \%)$ was the most common benign tumor and affected female patients more frequently. It is followed by Warthin's tumor that favored parotid gland. Adenoid cystic carcinoma was the most frequent malignant tumor followed by mucoepidemid carcinoma and carcinoma ex pleomorphic adenoma and the majorities were located in the submandibular gland.

Conclusion: In the present study, epidemiological data was compared with other worldwide series. Our retrospective study revealed that; benign tumors were more frequent, major salivary glands were more affected by both benign and malignant tumors than minor salivary glands and the parotid gland was the most affected site. Epidemiological data in the various parts of the world can be helpful for a better understanding of SGT's biology and characteristics.
\end{abstract}

Key words: Salivary gland, benign, malignant, tumors, epidemiology

\section{Introduction}

Salivary gland tumors (SGTs) consist of a group of heterogeneous lesions with complex clinicopathologic characteristics and distinct biological behavior that correspond to approximately $3 \%$ to $10 \%$ of the neoplasms of the head and neck region [1-5]. Epidemiological studies have shown geographical differences in the incidence and frequency of histological subtypes of SGTs [1]. In this retrospective study, hospital records of 244 patients with salivary gland tumors were documented with demographic features and histological diagnosis.

\section{Material and Methods}

Files of the Department of Pathology, from 1998 to 2014 were retrieved and 244 cases of salivary gland tumors were analyzed according to age, gender, location, size and histopathology of the tumor. In 4 cases bilateral tumors were present, hence 248 tumors were documented. Microscopic slides were reevaluated by 2 expert pathologists. All the tumors were classified according to the criteria suggested by 2005 WHO histological classification.

\section{Results}

Of 244 patients with salivary gland tumors, 128 were male $(52.5 \%)$, and 116 were female $(47.5 \%)$ and the mean age of the patients was 49.2 (min:5-max:86). The distributions of age, gender, tumor location, size, and histopathological diagnosis are summarized in table 1 . Of these 248 tumors $197(86.3 \%)$ were benign and 34 (\%13.7) were malignant. The mean age of the patients with benign tumors was 48.6 years (min:5-max:86), and that of those with malignancies was 55.3 years (min:21-max:81). The average size of benign tumors was $2.90 \mathrm{~cm}$ (min:0.70 cm-max:7 cm), while that of the malignant tumors was $3.77 \mathrm{~cm}$ (min:0.8 cm-max:8 cm). 
Most of the salivary gland tumors $(232 / 248,93.5 \%)$ originated from major salivary glands. The rest $(16 / 248,6.5 \%)$ originated from minor glands. The most common site was the parotid gland (207 cases, $83.5 \%$ ) followed by the submandibular (25 cases, $10.1 \%$ ) and minor ones (16 cases, 6.4\%).
Average size of PA cases were 2.83 (min:1 cm-max:7 cm), WT were $3.07 \mathrm{~cm}(\min : 0.70 \mathrm{~cm}-$ $\max : 7 \mathrm{~cm})$, ACC were $3.33 \mathrm{~cm}(\min : 0.8 \mathrm{~cm}$ $\max : 5.20 \mathrm{~cm})$, MEC were $3.08 \mathrm{~cm}(\min : 1 \mathrm{~cm}-$ $\max : 5 \mathrm{~cm})$ and CaexPA cases were $3.41 \mathrm{~cm}$ (min: $1.5 \mathrm{~cm}-\max : 6 \mathrm{~cm})$.

Table 1. Subtypes of SGTs up to topography, gender and tumor size . (PG: parotid gland, SMG: Submandibular gland, MSG: Minor salivary gland, PA: Pleomorphic adenoma, WT: Warthin's tumor, MEC: Mucoepidermoid carcinoma, CaexPS: Carcinoma ex pleomorphic adenoma)

\begin{tabular}{llllll}
\hline Tumors & PG n (\%) & SMGn(\%) & MSGn (\%) & $\begin{array}{c}\text { Gender n F/M (\%) } \\
\text { Average tumor size } \\
\text { (cm) (min-max) }\end{array}$ \\
\hline PA & $100(48.3)$ & $16(64)$ & $9(56.3)$ & $82 / 43(70.7 / 32.6)$ & $2.83(1-7)$ \\
WT & $75(36.2)$ & $2(8.0)$ & 0 & $11 / 66(9.5 / 50)$ & $3.07(0.7-7)$ \\
Basal cell adenoma & $5(2.4)$ & 0 & $1(6.3)$ & $3 / 3(2.6 / 2.3)$ & $1.86(0.8-3)$ \\
Oncocytoma & $2(1)$ & $1(4)$ & 0 & $1 / 2(0.9 / 1.5)$ & $3.3(3-4)$ \\
Myoepithelioma & $1(0.5)$ & 0 & $1(6.3)$ & $2 / 0(1.7 /-)$ & $1.95(1.4-2.5)$ \\
ACC & 0 & $5(20)$ & $3(18.8)$ & $4 / 4(3.4 / 3.0)$ & $3.33(0.8-5.2)$ \\
MEC & $6(2.9)$ & 0 & 0 & $3 / 3(2.6 / 2.3)$ & $3.08(1-5)$ \\
CaexPA & $4(1.9)$ & 0 & $2(12.5)$ & $3 / 3(2.6 / 2.3)$ & $3.41(1.5-6)$ \\
Adenocarcinoma, NOS & $3(1.4)$ & $1(4)$ & 0 & $1 / 3(0.9 / 2.3)$ & $4.37(3-7.5)$ \\
Asinic cell carcinoma & $3(1.4)$ & 0 & 0 & $3 / 0(2.6 /-)$ & $5.16(3.5-8)$ \\
Squamous cell carcinoma & $3(1.4)$ & 0 & 0 & $2 / 1(1.7 / 0.8)$ & $4.2(2-6.5)$ \\
Malignant oncocytoma & $2(1)$ & 0 & 0 & $0 / 2(-/ 1.5)$ & $4.5(3-6)$ \\
Epithelial-myoepithelial carcinoma & $1(0.5)$ & 0 & 0 & $0 / 1(-/ 0.8)$ & - \\
Ductal carcinoma & $1(0.5)$ & 0 & 0 & $0 / 1(-/ 0.8)$ & 4.5 \\
Giant cell tumor & $1(0.5)$ & 0 & 0 & $1 / 0(0.9 /-)$ & 3.5 \\
\hline
\end{tabular}

In the parotid gland there were 184 benign $(88.9 \%)$ and 23 malignant $(11.1 \%)$ tumors. In the submandibular gland $19(76 \%)$ cases were benign and $6(24 \%)$ were malignant. In the minor salivary glands $11(68.8 \%)$ cases were benign and $5(31.3 \%)$ were malignant.

Among the 248 salivary gland tumors 125 cases were pleomorphic adenoma (PA) (50.4\%) and 77 cases were Warthin's tumor (WT) (31\%). Among malignant tumors 8 cases were adenoid cystic carcinoma (ACC) $(3.2 \%), 6$ cases were mucoepidermoid carcinoma (MEC) $(2.4 \%)$ and 6 cases were carcinoma ex pleomorphic adenoma (CaexPA) (2.4\%).

The frequency of PA and WT among the benign tumors were $58.4 \%$ and $36 \%$ while the frequency of ACC, MEC and CaexPA were $23.5 \%$, $17.6 \%$ and $17.6 \%$. The frequency of PA, WT, ACC, MEC, CaexPA in female patients were $70.7 \%$, $9.5 \%, 3.4 \%, 2.6 \%, 2.6 \%$ while in male patients $32.6 \%, 50 \%, 3 \%, 2.3 \%, 2.3 \%$.

According to the location, $100(80 \%)$ cases of PA were located in the parotid gland, $16(12.8 \%)$ in the submandibular gland and $9(7,2 \%)$ in the minor salivary glands. WT were also common in the parotid gland (75 cases, $97.4 \%$ ) followed by the submandibular gland ( 2 cases, $2,6 \%$ ). On the other hand, the majority of ACC were located in the submandibular gland (5 cases, \%62.5) followed by the minor salivary glands (3 cases, 37.5\%). All cases of MEC ( 6 cases) occured in the parotid gland. 4 cases $(66.7 \%)$ of CaexPA were located in the parotid gland and $2(33.3 \%)$ in the minor salivary glands.

\section{Discussion}

SGT are a group of heterogeneous lesions with complex clinicopathological characteristics. Reports from several parts of the world have shown differences in epidemiology and incidence [1-11]. According to the World Health Organization and some previous studies, SGTs affect female patients more than males $[2,3,6]$. In a study with 3461 cases, Long-Jiang et al. reported the male:female ratio of 1.11/1 [7]. A study from Nigeria reported predominance for men with a male:female ratio of $1.4 / 1$ [12]. In the present study males $(52.5 \%)$ were also more frequently affected than females (47.5\%).

In the current study the mean age of patients was 49.2 and the mean age of patients with malignant neoplasia's was about 7 years higher than benign tumors $(55.3 / 48.6)$. In the study of Fonseca et al. with 493 cases, the mean age of patients with benign tumors was 46.3 and malignant tumors was 54.0 [1]. Long-Jiang et al. reported that the peak incidence age of benign tumor was third and fourth decades and of the malignant tumor was fourth and the fifth [7]. In the present study average size of benign tumors was slightly smaller than malignant tumors $(2.90 \mathrm{~cm} / 3.77 \mathrm{~cm})$. The average size of PA was $2.83 \mathrm{~cm}$, WT was $3.07 \mathrm{~cm}$, ACC $3.33 \mathrm{~cm}$, MEC was $3.08 \mathrm{~cm}$ and CaexPA was 3.41 $\mathrm{cm}$. In the series of Vargas et al. the average tumor size of PA was $3.12 \mathrm{~cm}$, WT was $4.15 \mathrm{~cm}$, ACC was $4.10 \mathrm{~cm}$, MEC $3.06 \mathrm{~cm}$ and CaexPA $3.30 \mathrm{~cm}$ [3].

The majority of salivary gland tumors in this study were located in the parotid gland $(83.5 \%)$ followed by the submandibular gland $(10.1 \%)$ and 
the minor salivary glands (6.4\%). In most of studies the parotid gland was the most frequent location (64-80\%) nevertheless frequency of tumor locations vary in different series [1, 2, 7]. Some authors reported less involvement of the parotid gland in salivary gland tumors, showing only $36.6 \%$ and $45.6 \%$ of the cases $[12,13]$.

In the present study $86.3 \%$ of the cases were benign and $13.7 \%$ were malignant, confirming the predominance of benign SGTs. In the literature it is reported that benign SGTs are more frequent than malignant tumors. In the study by Satko et al. with 1021 cases, benign SGT ratio was reported $74 \%$ and in another study by Tian et al. with 6982 cases that ratio was $68 \%$ [9]. All epidemiologic studies clearly show that PA is the most common benign salivary gland neoplasia. The frequency of PA among all salivary gland tumors published in the literature ranges from $40 \%$ to $72 \%$ [2]. In the series of 493 cases by Fonseca et al. the frequency of PA was $63.6 \%$ and in the series of 124 cases by Vargas et al. the frequency of PA was $59 \%[1,3]$. Likewise in the series of 496 cases by Ito et al. PA was determined the most frequent tumor comprising $54.2 \%$ of all SGTs and $80.3 \%$ of the benign tumors [2]. In our study the frequency of PA was detected $50.4 \%$ with 125 tumors among all SGTS and 58.4\% among benign tumors. Considering the gender of the patients PA was more frequent in females ( 82 females/43 males). On the contrary WT was more frequent in male (11females/66 males). A similar result was observed by Vargas et. al. According to their study PA was more frequent in females (55 females/29 males), WT was more frequent in males (10 males/3 females) [3].

In the present study, the most common malignant tumor was ACC and the majority of ACC were located in the submandibular gland followed by the minor salivary glands. This is in agreement with findings reported by some investigators [5, 12-15]. According to World Health Organization and some previous studies MEC is the most frequent malignant tumor and $\mathrm{ACC}$ is the second $[1,3,4,6]$.

\section{Conclusion}

In the present study, epidemiological data was compared with other worldwide series. Our retrospective study revealed that; benign tumors were more frequent in the salivary glands, major salivary glands were more affected by both benign and malignant tumors than minor salivary glands and the parotid gland was the most affected site. Pleomorphic adenoma was the most common benign tumor and affected female patients more frequently. The second most common benign tumor was Warthin's tumor which affected male patients more than females. Adenoid cystic carcinoma was the most frequent malignant tumor followed by mucoepidemid carcinoma and carcinoma ex pleomorphic adenoma. World-wide series show some differences in the incidence and clinicopathologic features of salivary gland tumors. Epidemiological data in the various parts of the world can be helpful for a better understanding of its biology and characteristics.

Financial Support: This research received no specific grant from any funding agency, commercial or not-for-profit sectors

Conflict of Interest: The authors declare no potential conflicts of interest with respect to the research, authorship, and/or publication of this article.

\section{References}

1. Fonseca FP, Carvalho Mde V, de Almeida OP, Rangel AL, Takizawa MC, Bueno AG, et al. Clinicopathologic analysis of 493 cases of salivary gland tumors in a Southern Brazilian population. Oral surgery, oral medicine, oral pathology and oral radiology. 2012;114(2):230-9.

2. Ito FA, Ito K, Vargas PA, de Almeida OP, Lopes MA. Salivary gland tumors in a Brazilian population: a retrospective study of 496 cases. International journal of oral and maxillofacial surgery. 2005;34(5):533-6

3. Vargas PA, Gerhard R, Araujo Filho VJ, de Castro IV. Salivary gland tumors in a Brazilian population: a retrospective study of 124 cases. Revista do Hospital das Clinicas. 2002;57(6):271-6.

4. Ansari MH. Salivary gland tumors in an Iranian population: a retrospective study of 130 cases. Journal of oral and maxillofacial surgery : official journal of the American Association of Oral and Maxillofacial Surgeons. 2007;65(11):2187-94.

5. de Oliveira FA, Duarte EC, Taveira CT, Maximo AA, de Aquino EC, Alencar Rde C, et al. Salivary gland tumor: a review of 599 cases in a Brazilian population. Head and neck pathology. 2009;3(4):271-5.

6. Barnes L, Eveson JW, Reichart PA, Sidranskiy D. World Health Organization classification of tumours. Pathology and genetics of head and neck tumours. Lyon, France: IARC. 2005;211-81.

7. Li LJ, Li Y, Wen YM, Liu H, Zhao HW. Clinical analysis of salivary gland tumor cases in West China in past 50 years. Oral oncology. 2008;44(2):187-92.

8. Kara MI, Goze F, Ezirganli S, Polat S, Muderris S, Elagoz S. Neoplasms of the salivary glands in a Turkish adult population. Medicina oral, patologia oral y cirugia bucal. 2010;15(6):e880-5

9. Tian Z, Li L, Wang L, Hu Y, Li J. Salivary gland neoplasms in oral and maxillofacial regions: a 23 -year retrospective study of 6982 cases in an eastern Chinese population. International journal of oral and maxillofacial surgery. 2010;39(3):235-42. 
10. Bello IO, Salo T, Dayan D, Tervahauta E, Almangoush A, Schnaiderman-Shapiro A, et al. Epithelial salivary gland tumors in two distant geographical locations, Finland (Helsinki and Oulu) and Israel (Tel Aviv): a 10year retrospective comparative study of 2,218 cases. Head and neck pathology. 2012;6(2):224-31.

11. Luksic I, Virag M, Manojlovic S, Macan D. Salivary gland tumours: 25 years of experience from a single institution in Croatia. Journal of cranio-maxillo-facial surgery : official publication of the European Association for Cranio-Maxillo-Facial Surgery. 2012;40(3):e75-81.

12. Otoh EC, Johnson NW, Olasoji H, Danfillo IS, Adeleke OA. Salivary gland neoplasms in Maiduguri, northeastern Nigeria. Oral diseases. 2005;11(6):386-91.
13. Kayembe MK, Kalengayi MM. Salivary gland tumours in Congo (Zaire). Odonto-stomatologie tropicale $=$ Tropical dental journal. 2002;25(99):19-22.

14. Satko I, Stanko P, Longauerova I. Salivary gland tumours treated in the stomatological clinics in Bratislava. Journal of cranio-maxillo-facial surgery : official publication of the European Association for Cranio-Maxillo-Facial Surgery. 2000;28(1):56-61.

15. Lima SS, Soares AF, de Amorim RF, Freitas Rde A. [Epidemiologic profile of salivary gland neoplasms: analysis of 245 cases]. Brazilian journal of otorhinolaryngology. 2005;71(3):335-40. 